\title{
Discussion on the Mode of Thinking Oriented Environment Art Design Work
}

\author{
Haijiao $\mathrm{Xu}^{1, \mathrm{a}}$ \\ ${ }^{1}$ Jilin Business and Technology College, China \\ Room 1001, Unit 1, Building No.12, Zone A, Greenland Xinli Center Mansion, Changchun City, Jilin \\ Province \\ azgccxhjiao@163.com
}

Keywords: Thinking, Thought way, Environmental, Art Design, Orientation

\begin{abstract}
Environmental art design is a creative thinking process with its own special logic and thought ways, according to which people think and work consciously and unconsciously. By knowing about this process and then consciously utilizing creative approaches, the design can be bettered scientifically, orderly and efficiently. This article attempts to explore the design based on the impacts that different thought ways exert on the designed works as well as the feedbacks from its receptors.
\end{abstract}

\section{Preface}

The mode of thinking influences the content and form of art design, which may also lead to the diversity of the proposition, and put aside the design, "environmental art design" itself contains a lot of different inter disciplinary content in "great range". Different ways of thinking can cause to form different works of art design.

\section{The Mode of Thinking Reflected In Environment Art Design Works}

Tony Buzan had once strongly recommended in his "Mind Map" that people could take advantage of thegraphical forms to accomplish various tasks, and he proposed a simple method of drawing mind maps, all mind maps have some things in common, They all use color, the natural structures emanating from the center, the use of lines, symbols, words and images, all followed by a set of rules that are simple, basic, natural and brain easily accepted. You can put a long list of boring information into diagram that is colorful, easily rememberedand highly organized through mind mapping which coincides with the naturally reflections in our brains. And in fact, it is also true in the early process of environment art design and it has gradually been recognized in human's brains.

Classification of Environmental Art Design Works. The emergence and development ofthe major of environmental art design actually is inevitably caused by the social division of labor from division tointegrity. It has gradually generated after a series of environmental problems have appeared during the process of industrialization with the strengthening of human environmental awareness. Environment art design pays close attention to human living facilities and space environment in the broad sense.it is the creation of human living space mainly through scientization, artistry and the coordination of human, building and environment to make them harmony and unity, and the forming of a complete, beautiful, comfortable space for human activities.

The human is always the theme and performance targets relating to environmental art design. Perhaps, with the further development and change of the times and the evolution of our way of thinking, the people-oriented principle that we have been emphasizing will be changed to "all living things-oriented".Therefore, it is our goal to create a space environment of human body science, adapting to the requirements of human activities and natural coexistence of mutually beneficial. So 
that the environment art design should be a return to nature, the respect for culture,a kind of high enjoyment and emotion, and tendencies of self-entertainment and personalization. Environmental art design in space form generally can be divided into the following types:

Urban planning. As a concept of environmental art design, the urban planning refers to making the compositive arrangements of the city construction and development in order to create a safe, healthy, convenient and comfortable urban environment for the city dwellers to meet their daily need of living and working.

Environmental art design. Environmental art design is to design the environment in aspects of structure, space, shape and function, including construction design and architectural design.

Interior design. Interior design, it is the design of interior architectural space. People are living in the interior space constituted by the building. This internal space is not a byproduct of environment design. On the contrary, it should be one of its main content.

Outdoor design. Outdoor environmental design refers to the design of all outside space of buildings, also known as landscape or landscape design including national forest design, courtyards, streets, parks, squares, roads, bridges, river, green and all other outdoor spaces of living areas, commercial and industrial areas, recreational areas and some of the independent outdoor space.

Public space design. Public space art design is a comprehensive design project developed in recent years, mainly the designs in public spaces for people like roads, railway stations and parks for the use of each individual with regional characteristics and rich cultural connotations.

The Limitation of Environmental Art Design. Nowadays, environmental art design has become an integral part of human cultureas both the carrier of society and culture or emotion expressions of artistic work, and a means of information exchange (media) or the "complex of matter and spirit". The study of environmental art and design are bound to not being limited to the range of subjects, but to go deep into more comprehensive and extensive exploration areas. We live in an information age with researchingat the trend of intersect of different disciplines especially the impact of different thinking modes on the forms of works.

Substance limiting. The building visual symbols inenvironmental art designs are composed by a specific substance material and subject to specific factors such as structure, construction law, construction and technical conditions, the particularity of these material factors will inevitably cause a certain system of symbols with some particularity.

The dual nature of the environment art design. Due to the complexity and contradiction of environmental art design, the mode of thinking also is of randomness and creativity, that is to say, it is not only made of matter and material substance but also limited by many factors. It is of functional "material form"and also a "significant form" with emotional and spiritual performancewhich is a clear and typical characteristic of"art symbol".

Art symbol has a dual symbolic meaning: "On one hand this symbol is in the form of a substance, on the other hand is the spirit of the performance," and both two are inextricably linked with each other.

The Mode of Thinking and the "Six Senses". Application of different forms of thinking is not only reflected in the conceptual age, but these six high-concept, high emotional ability can help people develop new thoughts required in this new era for the designs of environment art work, which are described below.

Expressing sense of design in environment art design works. Environmental art design work not only needs to be functional, but also a sense of design. Many people even believe that the national wealth and personal wellness depends on the presence of artists and designers. This illustrates the importance of designers engaged in design work, and environmental art design is extremely 
complex in design systems.

Story tellingin environment art design works. Environmental art design work is not only controversial, but also needs a sense of the story.

Our life is full of information and data, relying solely on the collection of information to prepare an effective debate is no longer enough, someone will pick you at any time in the wrong words to refute your point of view and refute your program. Persuasion, communication and basic self-understanding must be based on the narrative ability, and the sense of the story may be developed by human factors.

The integration ability of environment art design. Environment art design is not only a professional subject, but also needs the ability of integration.

Human factors facilitate the need of another ability that is the integrating capacity of the whole design and things, what is mostly needed now is not to analyze but with the integrating ability to see the whole, cross boundaries and integrate different things into new attractive things.

Resonant expression of environment art design work. It is both logical and resonant. We are the human because we have logical thinking abilities, but excellent logical thinking ability is rare in such an information age while advanced analysis tools are common in our daily lives. The human can understand motivations, are able to create good relationships with others and thinking of others. The resonant ability is mainly generated from the application of thinking modes.

It needs seriousness but also a sense of entertainment. Many evidences proof that laugh, good mood and humor are good for our mental health. Of course, we also need to be serious, but too serious and harsh will be adversely affected on your career and physical health. In concept age, regardless of work or life, we need to maintain loose attitude towards our lives.

Express a sense of significance. Not only to accumulate, but also needs to be meaningful. We live in a world of wealth materials, more and more peoplebegan to search for something more important out of the daily trivial matters: the purpose of life, the pursuit of excellence and spiritual satisfaction. the search for meaning is even more important, many people still do not understand when Mr. Pan Shiyi touched the "commune under the Great Wall", how can we suspect the "bamboo House"designed by Japanese designerNg Wei Yan because of the big sandstorm in Beijing?

\section{The Environment Art Design Work Is Characterized by Its Orientation}

The significance and process of environmental art design can influencehuman behavior in the following described way: various forms of cultural information and environment establish a fixed link inside in a particular culture, and the construction process of environment art design is the materialization process of cultural information (also is affected by other elementslike economy, climate and resources, etc.), it can still be called as the coding of information which can be understood and feltby people from the environment of the buildings, this can be seen as the decoding of the information, people will get this information and unknowingly respond appropriately toit.

Orientation. The so-called orientation can be understood as the synthesis of guidance and direction from the literal meaning of the word. But what herein described in this paper is the maverick guidance and recognizability of art design especially environment art design as mentioned in the previous section of this article thatenvironment art design works can make people engender the cognition and feelings for the work by awareness.

Further orientation should be two-way interaction, audience feedback information after designers face as he has done design work again should re-examine the kinds of information and feedback 
received from the positive point of view.

Information Feedback of the Designed works in Aspect of Aesthetic Appreciation. What the receivers want to get from the environment is not only the comfortable living conditions from the visual environment, but also need to keep abreast of the situation around, namely the timely perception of the information and changes in the surrounding environment, and the most important sense is of visual.

A good visual environment can be able to provide human with sufficient visual information. The outdoor sunlight and natural landscape of non-closed indoor space with windows plays a big role in the orientation, timing, nature and spatial guidance for the indoor visual environment. The impact of it affects humans sub consciously to a large extent. The normal environmental art design works are often not noticed by individuals is seen as a basic requirement of excellent works.

The form and function-oriented environment art design. The relationship between the form and function has been a fundamental problem in the theory research of environment art design, opinions in this theory vary for a long time and the extensive discussions also make people understand this issue more in-depth. Sullivan proposed the resounding slogan of modernism that is "the form follows function". Modernism emphasizes the leading role of the function with promoting the theory of "inside equals outside" in environment art design works which is seen as being opposed to the language symbols of classicism. Then the representative of modernism Venturi believed that the spatial form should follow the function and the external form is decided by the external environment,therefore inside cannot equal outside. This view of Venturi shows"the form has nothing to do with function." However, modern designers mainly insist that the "form and function"should not be concerned separately.A good work of environment art designisa unity of the organic combination of the two. The work, as to the audience, is a place for the manifestation of culture, inherit of spirit and sustenance of emotions, people's requirements in the aspect of spiritual expressions in art design work is a functional need of the work. This view can be called the"form is of functional". In fact here, the concept of"functional" has been greatly expanded.

The modernism not only emphasizes the demand of form and function in environmental artdesign work but also pay moreattention to the natural landscapes with ecological awareness. These landscapes meet people's need in the terms of sensory information, so it is often a higher pursuit to give expression to ecology and natural consciousness in modern environment art design works.

The Principle of the Orientation of Environmental Art Design. From the physical upbringing based on the natural ecosystems in the past to intelligent cultivation adapting to the culture of the information society, the people-oriented diverse environmental design elements can be summarized as the following aspects of content and requirements:

The space environment should meet the requirements of human activity.It is the basic condition to provide adequate space environment during the building of people-oriented environment art work.

The ecological environment must be conducive to human physiological requirements. The selection and creation of a good ecological environment is the prerequisite to implement people-oriented human settlements. The ecology of symbiotic and regeneration principle is of great significance to create a good living environment for people with the combination of nature and ecological cycle.

The visual environment is to meet the psychological requirements of the human. The design must meet people's psychological feeling by comfortable feelings in the visual environment. The residence, public facilities, comedy and green facilities must be coordinate withthe whole 
environment.

The cultural environment must achieve edifying requirements. The design should provide the people with an edifying and high-grade cultural environment. Environment art design is often combined with cultures of living, education, food and entertainment.

The intelligence environment is to expect people's need in information requirements. Based on the people-oriented target in such an information evolution age, new technologies must be considered to be created in aspects of computer networking, optical fiber communications, solar energy, water treatment, security alerts, disaster prevention and control as well as energy conservation and natural ventilation in order to meet the requirements in information and improve the efficiency of life.

\section{Conclusion}

The vast majority of human scientific thinking is stillof practical significance rather than the consideration of the existence or the ultimate meaning of life. Environmental art design work is composed of many parts with interactions among the parts. "In this system, the whole is greater than the sum of its parts. This is not of the ultimate and the sense of metaphor, but of important significance in practice." Human science may be endless in this complicated and diverse world, perhaps this "endless frontier" does not necessarily need to be really endless, but if human's complex ways of thinking are never able to grasp the point, then this "end" for the human will be just only an ideal castle in the air.As a result, the human's mind in the design can only be based on present environment. At the same time, we should vary our mode of thinking according tothe variable demands.

\section{References}

[1] Perspective Science of Painting [M]. Shanghai People's Fine Arts Publishing House, 2009, Y.Q.Hu.

[2] Perspective Science of Art and Design [M]. Shanghai People's Fine Arts Publishing House, 2005, Y. Bai.

[3] Practice of "scene alternate model"in Learning and Teaching of Environmental Art Design of Higher Vocational College [J],Journal of Sichuan Cadre Correspondence College, 2013 (01), L. Li.

[4] Study of Education Reform in Computer-aided Environment Art Design [J]. EDUCATION ARTICLE (HEAD), 2010 (10), A. Guo.

[5] Study of Space in Environment Art Design [J]. Enterprise Herald, 2010 (11), Y. Liu 